\title{
Harris's Coercive Discourse Is Stabilizing: Discourse Strategies and Effects
}

\author{
Abidi Hajer \\ Department of English, Faculty of Letters and Human Sciences of Sfax, Universtity of Sfax, Sfax, Tunisia \\ Email address: \\ abidihajer23@gmail.com \\ To cite this article: \\ Abidi Hajer. Harris's Coercive Discourse Is Stabilizing: Discourse Strategies and Effects Advances in Sciences and Humanities. \\ Vol. 7, No. 2, 2021, pp. 38-43. doi: 10.11648/j.ash.20210702.15
}

Received: April 25, 2021; Accepted: May 31, 2021; Published: June 16, 2021

\begin{abstract}
Since politicians make use of language in their quest to garner support and credibility, among other things, many coercive strategies are utilized by recourse to some manipulative avenues. These same coercive strategies happen in the matrix of a peculiar socio-cultural environment independently from ideologies and common or shared goals. The latter claims make this paper's focus manifold. Kamala Harris, the vice US President, opted for a number of stabilizing, as it seems, linguistic choices of diction, and thus messages to yield an automatic effect at a time of crisis. This research, in view of this, applies of qualitative method to analyze Harris's victory speech while implementing van Dijk's framework adopted from politics, ideology and discourse. In order to attain persuasive ends, some ideological macro-strategies have been widely invested in the speech like emphasizing Our Good things, de-emphasizing Their Bad things and so forth. Shaping public opinion has, thus, been coercively perceived via some ideological discourse categories like lexicalization, consensus and counterfactuals. Results show that coercive discourse has a stabilizing effect and is significantly linked to ideologies and political quibbles dissident from her predecessors. Results also show that coercion is endemic in political discourse and is overtly swinging in various directions to meet many ends.
\end{abstract}

Keywords: Ideologies, Coercive, Discourse, Stabilizing, Strategies

\section{Introduction}

The pre-election era in the United States has been stamped by a daunting economic, social and political state. During the election period, each candidate placed the onus of instability on his opponent's party leaders which lucidly reflected unrelenting convergence. As discourse is the real manifestation of language, and as a vice president of the United States, Harris, in her victory speech and to adapt to the shifting needs of the current perilous situation, opted for some strategies complying with the status quo. Indeed, dismantling the rhetorical strategies presupposes demystifying quibbles deployed in discourse via a critical discourse analysis framework.

This paper seeks to answer the following questions:

How efficient are the rhetorical strategies deployed by the vice president?

How did they reflect ideological mechanisms governing discourse?

What makes Harris's discourse different?

\section{Literature Review}

This part introduces the framework adopted in the analysis of political discourse and the theoretical model to be implemented.

\subsection{Critical Discourse Analysis}

Critical Discourse Analysis (CDA, henceforth) is not a single theory. Weiss \& Wodak [28] observe that several of identifiable strands are peculiar to CDA though they differ in methodology. These strands, in view of this, can be assumed to share common framework as well as a critical perspective [21]. Notwithstanding its added value to scholars, the criticism leveled at CDA puts into question the fact that it does not take into account the role of the reader at the level of interpretation [7, 14, 27]. On the other hand, Chilton [3] criticizes the aims of CDA as people are biologically equipped to recognize ideological processes that underlie text production which makes CDA efficacy questionable. Despite 
the criticisms abound to CDA Fowler [7] contends that the task of critical discourse analysts is to identify both manipulation and ideology of a text which is "below the threshold of notice". This means, among other things, that the analyst is equipped with a variety of theoretical tools to uncover hidden, manipulative and ideological mechanisms. No far from the latter view, van Dijk [21] defines CDA as a "research enterprise which critically analyzes the relationship between language and society. In conjunction with the aforementioned claim, Fairclough and Wodak [28] limit the scope of CDA in the fact that it addresses social problems, as it is a form of social action. Additionally, discourse is claimed to have an ideological work and power relations are themselves discursive. Being historical, discourse is assumed to constitute both society and culture which makes the link between text and society mediated.

Despite the criticism relative to CDA paradigm, one of the robust evidences that make CDA operative and compelling is the fact that it makes use of linguistic tools and rhetorical strategies to critically analyze discourse which exhibit meaning implications and manipulative language use, in addition to other discourse aims which are prone to appear in everyday conversations, media or political discourse.

\subsection{Social Cognition}

Studying discourse presupposes the cognitive dimension which has a mediating role between society and cognition. In view of this, van Dijk defines social cognition as "a system of mental representations and processes of group members" [19]. The latter is connected to social memory, which means that cognitive processes are defined in relation to memory, more precisely Short-term Memory and Long-term Memory (LTM, henceforth). LTM is broken into two types: Episodic Memory (EM, henceforth) and Semantic Memory (SM, henceforth). Concerning EM it stores information based on personal experiences. SM, however, stores more general, abstract and socially shared information like knowledge of language or knowledge of the world [22].

Interestingly, Serber observes that a distinction has to be made between testimony and argumentation. For testimony to be accepted, text producers should give reasons so they accept or refuse such representations [17] though text producers can achieve the effect of making text consumers take peculiar attitudes towards people, objects, etc [17]. Hence, during discourse, text consumers check for internal and external coherence while referring to logical relationships set between sentences, clauses and commitments [12]. Since one of the ultimate objectives of politicians is to reach legitimacy, there should be, as Hart contends, "an intention to overcome text-consumers, logicorhetorical module, which displays both internal and external coherence. Whereas coherence pertains to the text metafunction, external coherence relates to the interpersonal metafunction and this is likely to be conveyed through evidentiality and modality [1]. The latter tools of analysis as previously mentioned might be relevant to the analysis of the same discourse genre, and this might generate and solve many meaning intricacies. This implies, as well, that some other tools are prone to be assigned the same role for a variety of objectives.

Fetzer\& Lauerbach [9] put forward an interesting view stating that public communication is merely discursive. As it is stated by the authors, public actors in speech production make use of a number of strategies like setting agendas, selecting topics, positioning the self and the other in specific relationships, making assumptions, etc. In the same connection, Chilton [2,4] observes that certain texts yield automatic effects. Such coercive tactics, thus, generally include legitimization whereby the speaker has a particular social role and authority [13]. The major aim, in this regard, is to mobilize people towards a central goal [10]. This same view is discussed in depth by van Dijk [25]. This is going to be further accounted for in the below part.

\subsection{Ideology}

There is still no consensus in how to define ideology as theories, each from its perspective, link it to some particular thorny issues. This means that there is a constant clash of standpoints. However, some recent identifications of the concept have been hovering between the social, cognitive, cultural dimensions and so forth. Ideology is defined by van Dijk as the legitimate power abuse, basically if subordinated groups accept that as natural [25]. He, for instance, summarizes ideologies as being both social and cognitive, a view that links the social dimension to cognition. Furthermore, these are stored in LTM, and are thus, socially shared. Since they are shared, group identity is based not only on their structural proposition but also on their ideology. What is peculiar about ideologies is that they form the basis of beliefs and opinions and they are not necessarily negative. Interestingly, they are structured by a social schema that consists in a number of categories representing group dimensions, goals, actions and values. And this makes group members share the same level of ideological knowledge or expertise. Discourse, then, makes them observable [25]. As a system of beliefs ideologies, as van Dijk observes [26], are reflections of common opinions, ideas and so forth, whose main task is to guide the interpretation of both events and "monitor their social practices".

An interesting standpoint by Dant [26] states that "ideology is the determinative relationships between the social and the material conditions of existence and the abstract relations construed in knowledge". This mere view is not mutually exclusive with van Dijk's assumption; the social dimension and the cognitive one are significantly present. On the other hand, Eagelton, who approaches ideology differently, [6] considers that ideology has a pejorative ring as it evokes a whole array of negative emotions, a view that has to be taken with caution. In further analyzing ideology, he comes to the assumption that ideology is the study of knowledge of ideas as a social phenomena, a view that has common aspects with van Dik's assumption, where the social dimension is one of the constituents of ideological drives [19]. He, in parallel, adds that "ideology is a set of discursive 
strategies for legitimizing a dominant power" [6]. In an attempt to draw the dividing lines between culture and ideology, he assumes that what is meant by 'cultural' is the "points at which our cultural practices are interwoven with political power" [6]. And thus, society and culture, while interwoven, identify ideology.

The above claims mean, among other things that, some coercive effects, ardently in so many cases, are met. The latter effects, thus, are context dependent as it might be assumed. It, perhaps, seems a little bit hard to nip around the screen to dismantle such effects, but thorough discourse strategies the task's complexity may be askew. Inherent in discourse is the notion of legitimation, the latter is to be accounted for in the below section.

Suffice it to say that legitimizing strategies are argumentative forms. They target knowledge or assertions of the speaker, in conjunction with his status. These strategies can be related to both logos (appeal based on logic and reason) and ethos (appeal based on character) in rhetoric. In line with this, text producers have a considerable capacity in "expressing the continuity between propositions commitment towards the truth of propositions and evidence for their truth" [12]. To proceed, the below figure accounts for both types of coherence:

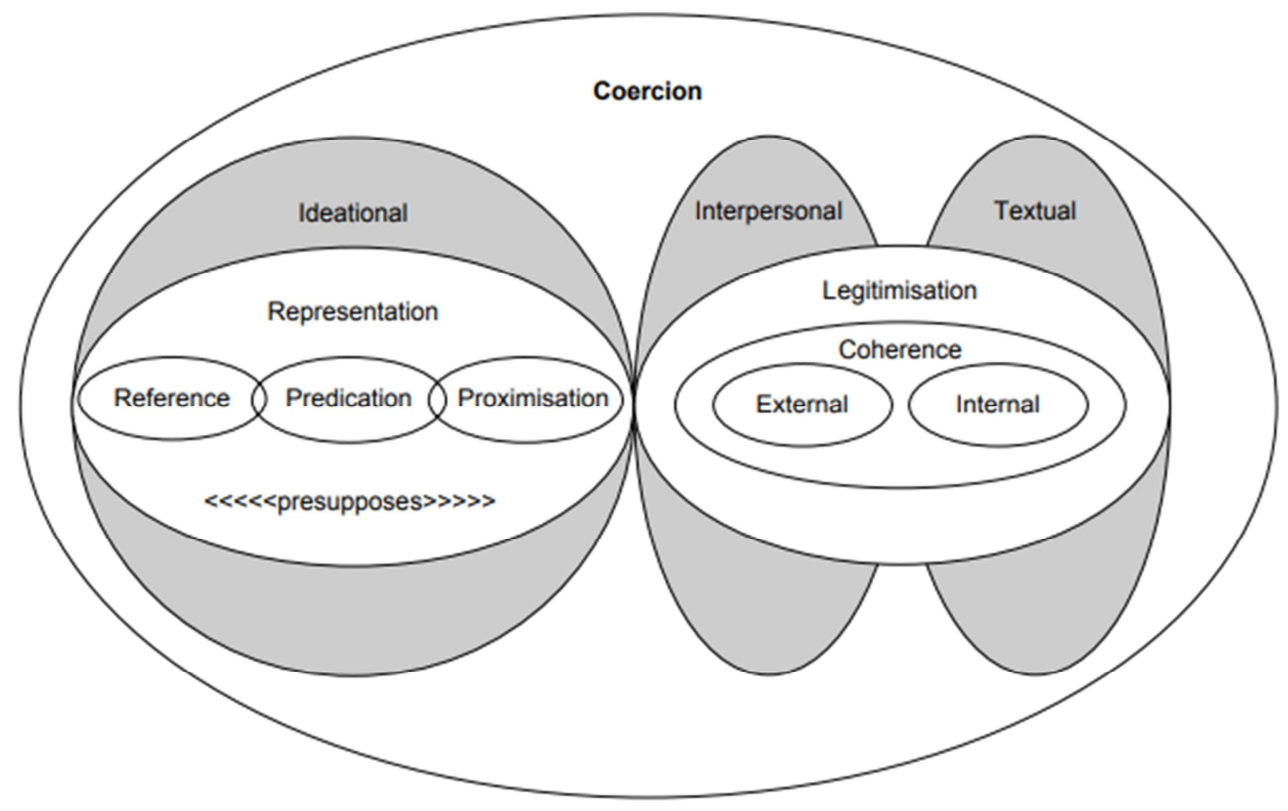

Figure 1. Strategies and functions: Halliday and Hasan 1976 cited in [12]

The figure both visualizes and accounts for grammatical cohesion and some semantic category basically evidentiality and epistemic modality. During discourse, receivers check internal and external coherence. Whereas internal coherence pertains to logical relationships between sentences, internal coherence is connected to the meta-function of the language (interpersonal) [12].

One of the interesting classifications of strategies of legitimization has been adopted by Reyes [16]. These strategies consist in emotions (basically fear), a hypothetical future, rationality, voices of expertise and finally altruism. The author observes that "language refers to the process by which speakers accredit or license a type of social behavior". Interestingly, Ochs [15] maintains that intentionality is the core of language and political discourse. In view of this, legitimization is the mere act of legitimizing this kind of behavior via argumentation to seek support and approval. The ultimate aims are to monitor power, achieve social acceptance, improve community relationships, seek popularity and fame while presenting one's proposal as the right and appropriate one. In so doing, and by triggering coercive behavior, certain core structures of legitimization would respond to cognitive structures [16].

\section{Methodology}

In this section, the corpus is going to be described in addition to the selection criteria, the methods and the tools of analysis.

\subsection{Corpus and Selection Criteria}

This small-scale corpus, short as it may appear, consists in the victory speech of Kamela Harris, the US vice president. It was delivered on November 7, 2020. The speech has been retrieved from the following address: https://www.youtube.com/watch?v=-xOJJXm6enA.

\subsection{Methods of Analysis}

In order to analyze the victory speech, a qualitative method of analysis is going to be invested. The latter analysis is going to be grounded on and supported by examples of the manuscript.

\subsection{Analytical Framework}

It is customary in CDA that the analysis is carried out 
while adopting one of the relevant frameworks. By recourse to van Dijk's analytical framework [25], this speech is going to be investigated. This framework is based on the belief that ideologies have a polarized structure, which reflects competing or even conflicting group membership and categorization in in-groups and out-groups [25]. The overall strategies of text and talk are the following:

1) Emphasize Our good things

2) Emphasize Their bad things

3) De-emphasize Our bad things

4) De-emphasize Their good things

Some of the categories are going to be utilized in text analysis to dismantle ideologies which are expressed in various structures. There is a considerable number of these structures but only few ones are invested, in this regard. Actor description as one of the structures deployed refers to the ways actors are described is ideology-laden. Authority (argumentation) as another structure typically stands for how people with particular ideologies cite some authorities. Categorization, as the concept suggests, refers to the way people and are categorized. On the other hand, consensus envisages a practical strategy for which politicians opt. Once the country is threatened, this strategy seems to be efficient in collecting support so as to reach stabilizing effects. Zooming on Positive self-presentation and negative other-presentation, these can be perceived through examples and illustrations by providing concrete arguments. One more strategy is manifested in implication whereby the political actor does not say everything but the recipient has to fully understand the implied meaning which is back-grounded while relying on their shared knowledge and opinions.

It, then, comes as no surprise that the above tools of analysis constitute, by the same token, effective analytic instruments for text analysis as they are embedded in discourse. Consequently, these same elements are effective as they have a significant role as they contribute to generating new sub-categories within the same tool.

\section{Results and Discussion}

In a critical discourse analysis of the victory speech of the US vice president, kamala Harris, some analytic tools are deployed adopted from the theoretical approach of van Dijk [23]. In this small-scale research, short as it may appear, one strategy utilized by the vice president within the matrix of ideological drives, is manifested in actor description. Positive and negative presentations are to support the internal fissures of this rhetorical strategy which hide group and party conflicts and these define identity. The below extract is to account for the first strategy:

You chose Joe Biden as the next president of the United States of America. And Joe is a healer, a uniter, a tested and steady hand, a person whose own experience of loss gives him a sense of purpose that will help us, as a nation, reclaim our own sense of purpose. And a man with a big heart who loves with abandon. It's his love for Jill, who will be an incredible first lady. It's his love for Hunter, Ashley and his grandchildren, and the entire Biden family.

In addition to other social actors, Harris blatantly mentioned Biden at the beginning of her address. The latter has been paid, as seen in the extract, much attention. He is actually placed in the long lineage of US presidents who have been positively represented throughout history. Harris, from this regard, seems, in a compelling fashion, to build a positive image while alluding tacitly to his predecessor who caused divide and disunity in the nation. The vice president presents Biden as the right leader who can adapt to the grapple of the shifting needs of the future while withholding much of the achievements of Trump who has been attributed the responsibility of the state of disarray. The positive presentation of the US president is not ideology free and this is manipulative and seems, as well, to be purposeful. A range of ideals and shared knowledge have reverberated across the extract such as those of hard work, family ties, engagement, patriotism and so forth. Other ideological doctrines appear obvious among them the celebration of the Democratic Party's success whose essence matches with a system of beliefs that is common among adherents and friends worldwide.

The second rhetorical strategy, which shrewdly defines the self and the other, is authority. This is achieved by means of argumentation in favor of a particular political actor. This has been observable in the portrayal of Joe Biden, the presidentelect and Harris's mother. The extract that comes next is a case in point:

When she came here from India at the age of 19, she maybe didn't quite imagine this moment. But she believed so deeply in an America where a moment like this is possible. And so, I'm thinking about her and about the generations of women - Black women, Asian, White, Latina, Native American women who throughout our nation's history have paved the way for this moment tonight.

Harris's mundane but wise reference to her mother, races and origins is not ideology free. It comes as no surprise that the overt alignment with an American homogeneous society is an argumentative strategy which generates intense and unifying goals. This persuasive means of argumentation in a precarious situation seems to be blameful though in a tacit fashion for the looming perils. Foregrounding the role of women and races in general in a multi-cultural society is purposeful. Sifting through the extract, it has been clearly understood that no future sexist and racist attacks are allowed. At the heart of the discourse provided lie previous discourses. It is true that no direct and overt reference to Trump has been observable, but a critical and contextual analysis with reference to the general context helps decipher the intended message, which is positive and compelling given its exquisite content at least for minorities who have been vilified in social media (like twitter). Hence, as discernible, positive representation of the self and the other who is rated a friend, supporter or else, is anchored throughout the story told by Harris in compliance with the political agenda she makes an integral part of. Authority of the speaker to select the topics and argue in favor of them has been clear as no interruptions were provided. Authority, then, is 
multi-dimensional; it allows the speaker to communicate beliefs, ideologies, plans, and it seems to share group identity which embody the general principles governing the community. Zooming on the next rhetorical and persuasive strategy in the text, one has to cover in a next stage consensus.

And to the American people: No matter who you voted for, I will strive to be a vice president like Joe was to President Obama - loyal, honest and prepared, waking up every day thinking of you and your family.

Akin to the previous extracts, as pinpointed by Harris, consensus is prioritized to opt for stabilizing effects and seek unity. As a rhetorical strategy, consensus is sought overtly while pledging the people of good will based on collective beliefs which are ideology-laden. At this very level discourse plays a role at the reproduction of ideologies since it is communicated with the intention to set a new agenda. Interestingly, Harris opts for actor description strategy to strengthen her argument and render her statement more believable while referring to Obama, one of the former presidents of the USA. It stands to reason, then, that Harris's discourse is coherent and understandable as it opts for everyday language that needs no knowledge to be understood. The next strategy is manifested in examples, illustrations and implication since these two strategies allude to some particular issues:

Because now is when the real work begins. The hard work. The necessary work. The good work. The essential work to save lives and beat this pandemic. To rebuild our economy so it works for working people. To root out systemic racism in our justice system and society. To combat the climate crisis. To unite our country and heal the soul of our nation.

Given the current destabilizing pandemic and racial matters, the environmental issues, the economic recession, which can be categorized as health, economic and social and/or race challenges, the vice president has given concrete solutions and without mitigation. The state of disarray is acknowledged as acute. And thus, what is implied is an affinity in standpoints to face the consequential matters. Additionally, what is implied in the extract above is the old political agenda. Hence, in an attempt to set a new one, Harris presents proactive efforts in response to the weak governance. These implied meanings are obviously to direct the attention of the audience to the shortcomings of the Republican Party's management. In tandem with the previous strategies, positive self-presentation and negative other presentation are two rhetorical tools invested by political actors in both text and talk. In the extract that follows, this strategy is going to be further analyzed:

And the road ahead will not be easy. But America is ready, and so are Joe and I.

We have elected a president who represents the best in us. A leader the world will respect and our children can look up to. A commander in chief who will respect our troops and keep our country safe. And a president for all Americans.

As discernible in the above extract, emphasizing OUR good things is overt. What is remarkable, however, is the act of deemphasizing THEIR good things (Republicans). Hence, emphasizing THEIR good things has been missing. On the contrary, self-glorification has been recurrent. Opting for a strategy that keeps the OTHER distant and absent in discourse is not random. At the heart of this dissident discourse type lie many queries. This, presumably, is redirect attention to one target: the Democratic government and his new agenda independently from the opponents' past rule. After race, economic and health issues came to the fore, the new operative governance attempts to, under the synergies of all Americans and leadership, unite the people and fight new arising problems especially race and health ones.

The different strategies adopted from van Dijk's approach [23] have shown a large amount of efficiency in the analysis of the victory speech. Although the rhetoric utilized in rudimentary, she opted for equivocation in some occasions while alluding the previous government. Much resilience has been observable though many clichéd linguistic expressions were invested which touch emotions such those of love.

It has also been discernible that negative other-presentation has been absent from discourse though positive-self presentation has been prevalent. This might, to a large extent, amount to the fact that the ideological drives and political agenda sought in the new Democratic government seeks unity, looks forward to solve economic, health and race matters. Unlike Trump's discourse which has been stamped by continuous attacks of the other. Harris's one is deemed stabilizing, uniting and most of all sounds adapted to the shifting needs of the current and future precarious situation. Interestingly, it has been mentioned in the methodology chapter that four major strategies are by default relevant to the analysis of discourse. In view of this, emphasizing OUR good things has been observable in discourse contrary. The act of emphasizing their BAD things has been totally absent, it was rather implied. As for the next two strategies precisely de-emphasizing our BAD things this has been remarkable as no single bad thing has been mentioned. In parallel, deemphasizing their GOOD things has also been missing.

Hence, these discourse strategies have been utilized wisely by the vice president to persuade the public, generate positive future plans, unite the nation and go beyond the state of disarray. Indeed, investing linguistic tools such as van Dijk's approach [23] within critical discourse analysis framework has also been utilized by some previous research in an attempt to study language use in society and legitimation. The bulk of research included the following scholars, among many researchers, Wodak [28], van Dijk [25], van Leeuwen [26][22]. One interesting method of analysis encompassing many strategies by Rayes [16] provides some distinct and relevant elements: emotions (fear), a hypothetical future, rationality, voices of expertise and altruism.

The strategies adopted by Rayes [16] seem to be relevant and efficient to the analysis of political discourse, though.

\section{Conclusion}

This paper was written with the intention to critically analyze the victory speech of the vice president Kamala 
Harris. After applying van Dijk's approach [23], strategies of discourse selected in the analysis have shown efficiency though some of them were irrelevant like negative OTHER presentation and emphasizing THEIR bad things. These very particular strategies have not been invested as manipulative and rhetorical discourse tools. Kamala Harris, then, has opted purposefully to positive self-presentation and the emphasis of GOOD things, while totally back-grounding the OTHER (Like Trump). As such, back-grounding as another strategy of discourse might be utile to decipher meaning implications.

This piece of research has attempted to cover the different rhetorical strategies deployed for some political actors' ends. However, it has some limits. Other discourse strategies might be relevant like the ones adopted by Reyes [16]. Additionally, pragmatics might also be integrated with critical discourse analysis to achieve compelling results. It has also bridged the gap in the literature which assumes that discourse strategies include the ones provided by van Dijk by zooming on legitimation, manipulation and back-grounding in addition to the choice of diction and rhetoric.

\section{References}

[1] Brown, G. and G. Yule (1983). Discourse analysis. Cambridge: Cambridge University Press.

[2] Chilton, P. (2004). Analysing political discourse: Theory and practice. London: Routledge.

[3] Chilton, P. (2005b). Manipulation, memes and metaphors: The case of Mein Kampf. In L. de Saussure and P. Schulz (eds), Manipulation and ideologies in the twentieth century. Amsterdam: John Benjamins. pp. 15-44.

[4] Chilton, P. (2014). Language, space and mind: The conceptual geometry of linguistic meaning. Cambridge: Cambridge University Press.

[5] Dant, T. (2013). Knowledge, ideology \& discourse: A sociological perspective. Routledge.

[6] Eagleton, T. (2014). Ideology. Routledge.

[7] Fowler, R. (1991). Language in the news: Discourse and ideology in the press. London: Routledge.

[8] Fowler, R. (1996). On critical linguistics. In C. R. CaldasCoulthard and M. Coulthard (eds), Texts and practices. London: Routledge. pp. 3-14

[9] Fetzer, A. \& G. Lauerbach (Eds.). (2007). Political discourse in the media. Amsterdam: John Benjamins.

[10] Hartman, R. (2002). The knowledge of good: Critique of axiological reason. Amsterdam: Rodopi.

[11] Huntington, S. (2004). Who are we: The challenges to America's national identity. New York: Simon \& Schuster.
[12] Hart, C. (2010). Critical discourse analysis and cognitive science: New perspectives on immigration discourse. Springer.

[13] Martin, J. R. \& R. Wodak (Eds.). (2003). Re/reading the past. Critical and functional perspectives on time and value. Amsterdam: John Benjamins. McGray, D. (2003). The minister of net defense. Wired 11. http://www.wired. com/wired/archive/11.05/schmidt.html.

[14] O'Halloran, K. (2003). Critical discourse analysis and language cognition. Edinburgh: Edinburgh University Press.

[15] Ochs E (1979) Planned and unplanned discourse. In: Givón T (ed.) Syntax and Semantics 12: Discourse and Syntax. New York: Academic Press, 51-80.

[16] Reyes, A. (2011). Strategies of legitimization in political discourse: From words to actions. Discourse \& Society, 22 (6), 781-807.

[17] Sperber, D. (2001). An evolutionary perspective on testimony and argumentation. Retrieved 20 June, 2008, $\mathrm{http} / / /$ sperber.club.fr/index.htm.

[18] Weiss, G. and R. Wodak (2003). Introduction: Theory, interdisciplinarity and critical discourse analysis. In G. Weiss and R. Wodak (eds), Critical discourse analysis: Theory and interdisciplinarity. Basingstoke: Palgrave. pp. 1-35.

[19] Van Dijk, T, A. (1995). Discourse analysis as ideology analysis. In C. Schäffner and A. I. Wenden (eds), Language and peace. Amsterdam: Harwood Academic Publishers. pp. $17-36$.

[20] Van Dijk, T. A. (Ed.). (1997). Discourse as social interaction (Vol. 2). Sage.

[21] Van Leeuwen, T. (1996). The representation of social actors. Texts and practices: Readings in critical discourse analysis, 1 , 32-70.

[22] Wodak, R. (1999). Critical discourse analysis at the end of the 20th century. Research on Language \& Social Interaction, 32 (1-2), 185-193.

[23] Van Dijk, T. A (2001). Critical discourse analysis. In D. Schiffrin, D. Tannen and H. E. Hamilton (eds), The handbook of discourse analysis. Oxford: Blackwell. pp. 352-71.

[24] van Dijk, T, A. (2002). Ideology: Political discourse and cognition. In P. Chilton and C. Schäffner (eds), Politics as text and talk: Analytic approaches to political discourse. Amsterdam: John Benjamins. pp. 203-38.

[25] Van Dijk, T, A. (2004) Politics, Ideology and Discourse. Retrieved from http://www.discourses.org/

[26] Van Dijk, T. A. (2013). Ideology and discourse. The Oxford handbook of political ideologies, 175-196.

[27] Van Leeuwen, T. \& R. Wodak. (1999). Legitimizing immigration control: a discourse-historical analysis. Discourse Studies, 10, 83

[28] Widdowson, H. G. (2004). Text, context, pretext: Critical issues in discourse analysis. Oxford: Blackwell. 